\title{
Aeronave Remotamente Pilotada (RPA) para aplicação de agrotóxico
}

\author{
Remotely Piloted Aircraft (RPA) for pesticides application \\ Aviones Pilotados a Distancia (RPA) para aplicación de pesticidas
}

Recebido: 14/09/2021 | Revisado: 19/09/2021 | Aceito: 20/09/2021 | Publicado: 21/09/2021

\author{
Jorge Olindo Silva Neto \\ ORCID: https://orcid.org/0000-0002-4624-6503 \\ Instituto Federal de Minas Gerais, Brasil \\ E-mail: jorgeolindoribeiro@gmail.com \\ Robson Shigueaki Sasaki \\ ORCID: https://orcid.org/0000-0001-8262-5781 \\ Instituto Federal de Minas Gerais, Brasil \\ E-mail: robson.sasaki@ifmg.edu.br \\ Cleyton Batista de Alvarenga \\ ORCID: https://orcid.org/0000-0002-0431-6171 \\ Universidade Federal de Uberlândia, Brasil \\ E-mail: cleytonalvarenga@ufu.br
}

\begin{abstract}
Resumo
É crescente o uso de sistemas remotos para aplicação de agrotóxicos, entretanto, observa-se a carência de estudos relacionados ao tema. O presente trabalho teve como objetivo desenvolver e avaliar uma aeronave remotamente pilotada (RPA) para a aplicação de agrotóxicos. Inicialmente, projetou-se a RPA, e construiu-se com poliestireno extrudado de $5 \mathrm{~mm}$ e isopor t7. Após a construção da RPA foi instalado um sistema de pulverização hidráulica constituído de bomba hidráulica; Tanque com capacidade de $0,350 \mathrm{~L}$ e pontas Jacto ${ }^{\circledR}$, cone vazio, modelo JD12P. Posteriormente, realizaram-se testes de eficiência de aplicação. Montou-se um experimento, em condições de laboratório, em delineamento inteiramente casualizado, em esquema fatorial (3x7), três alturas de voos $(1,0 ; 2,0$ e 3,0 $\mathrm{m})$ e sete posições de etiquetas hidrossensíveis no solo $(-1,5 ;-1,0 ;-0,5 ; 0,0 ;+0,5 ;+1,0+1,5 \mathrm{~m})$. O pulverizador foi previamente aferido quanto a vazão de líquido e velocidade do voo, o qual apresentaram valores de $0,160 \mathrm{~L} \mathrm{~min}^{-1}$ por ponta e velocidade do voo de $20 \mathrm{~km} \mathrm{~h}^{-1}$, respectivamente. As pulverizações foram realizadas nas referidas alturas, na posição 0,0 . A referência com sinal negativo trata-se da deposição a esquerda do sentido de deslocamento e sinais positivo deposição a direita do sentido de deslocamento. Após as pulverizações, as etiquetas foram digitalizadas e submetidas a análise. A RPA apresentou melhor características de deposição no alvo, quando operou na altura de voo de $1 \mathrm{~m}$. O sistema possibilita aplicação em áreas localizadas principalmente em plantas perenes de elevado porte.
\end{abstract}

Palavras-chave: RPA; Altura de voo; Etiquetas hidrossensíveis.

\begin{abstract}
The use of remote systems for the application of pesticides is growing, however, there is a lack of studies related to the subject. The present work aimed to develop and evaluate a remotely piloted aircraft (RPA) for the application of pesticides. Initially, the RPA was designed, and it was built with $5 \mathrm{~mm}$ extruded polystyrene and $\mathrm{t} 7 \mathrm{Styrofoam}$. After the construction of the RPA, a hydraulic spraying system consisting of a hydraulic pump was installed; Tank with capacity of $0.350 \mathrm{~L}$ and Jacto® spray nozzles, empty cone, model JD12P. Subsequently, application efficiency tests were carried out. An experiment was set up, under laboratory conditions, in a completely randomized design, in a factorial scheme (3x7), three flight heights $(1.0,2.0$ and $3.0 \mathrm{~m})$ and seven positions of water sensitive papers in the soil $(-1.5 ;-1.0 ;-0.5 ; 0.0 ;+0.5 ;+1.0+1.5 \mathrm{~m})$. The sprayer was previously checked for liquid flow and flight speed, which presented values of $0.160 \mathrm{~L} \mathrm{~min}^{-1}$ per spray nozzle and flight speed of $20 \mathrm{~km} \mathrm{~h}^{-1}$, respectively. The sprays were carried out at these heights, at the 0.0 position. The reference with a negative sign refers to the left-hand position of the travel direction and the positive signs to the right-hand position of the travel direction. After spraying, the tags were scanned and submitted for analysis. The RPA showed better target deposition characteristics when operated at a flight height of $1 \mathrm{~m}$. The system allows application in areas located mainly in large perennial plants.
\end{abstract}

Keywords: RPA; Flight heights; Water sensitive papers.

\section{Resumen}

El uso de sistemas remotos para la aplicación de pesticidas es cada vez mayor, sin embargo, hay una falta de estudios relacionados con el tema. El presente trabajo tuvo como objetivo desarrollar y evaluar una aeronave pilotada a distancia (RPA) para la aplicación de pesticidas. Inicialmente, se diseñó el RPA y se construyó con poliestireno extruido de $5 \mathrm{~mm}$ y espuma de poliestireno t7. Después de la construcción de la RPA, se instaló un sistema de pulverización hidráulico que consta de una bomba hidráulica; Depósito con capacidad de 0.350 L y boquillas de 
difusión Jacto®, cono hueco, modelo JD12P. Posteriormente, se llevaron a cabo pruebas de eficiencia de la aplicación. Se montó un experimento, en condiciones de laboratorio, en un diseño completamente aleatorizado, en un esquema factorial $(3 \times 7)$, tres alturas de vuelo $(1.0,2.0$ y $3.0 \mathrm{~m})$ y siete posiciones de papel sensible al agua en el suelo $(-1.5 ;-1.0 ;-0.5 ; 0.0 ;+0.5 ;+1.0+1.5 \mathrm{~m})$. El boquillas de difusión fue previamente revisado para flujo de líquido y velocidad de vuelo, los cuales presentaron valores de $0.160 \mathrm{~L} \mathrm{~min}^{-1}$ por boquilla y velocidad de vuelo de $20 \mathrm{~km} \mathrm{~h}^{-1}$, respectivamente. Las pulverizaciones se realizaron a estas alturas, en la posición 0.0. La referencia con un signo negativo se refiere a la posición a la izquierda del sentido de la marcha y los signos positivos a la posición a la derecha del sentido de la marcha. Después de la pulverización, las etiquetas se escanearon y se enviaron para su análisis. El RPA mostró mejores características de deposición del objetivo cuando se opera a una altura de vuelo de $1 \mathrm{~m}$. El sistema permite su aplicación en áreas ubicadas principalmente en grandes plantas perennes.

Palabras clave: RPA; Altura de vuelo; Papel sensible al agua.

\section{Introdução}

Os agrotóxicos são utilizados para combater pragas, doenças e plantas daninhas. A ferramenta mais utilizada para proteger as lavouras dos ataques de patógenos e insetos, de forma rápida, tem sido a aplicação de produtos fitossanitários, por meio da pulverização (Ferreira et al., 2013). Existem diversas formas para realizar a aplicação de agrotóxicos, desde equipamentos costais manuais até equipamentos aéreos. Essa variação pode ocorrer devido ao tamanho da área, características da cultura e do alvo a ser atingido.

As máquinas agrícolas estão em constante evolução, e, atualmente, na era da "Agricultura 4.0" as transformações digitais e a tecnologia aparecem no setor agrícola de várias formas. Entre as ferramentas e tecnologias, encontram-se as Aeronaves Remotamente Pilotadas (RPAs). De acordo com a Agência Nacional de Aviação Civil (Anac), RPA é aquela em que o piloto não está a bordo, mas controla a aeronave remotamente por meio de uma interface (computador, simulador, dispositivo digital, controle remoto, etc).

O Sindicato Nacional das Empresas de Aviação Agrícola (Sindag, 2017) relata que os drones serão substitutos de boa parte dos aparelhos de pulverização, trazendo precisão e segurança na operação. Diversas vantagens podem ser atribuídas ao uso de RPAs na agricultura. Verger et al. (2014) e Gao et al. (2018), relatam o baixo custo financeiro e alta flexibilidade. Ainda as RPAs permitem aplicação em áreas de difícil acesso, áreas muito íngremes ou com obstáculos onde os demais pulverizadores não conseguem operar. O drone também permite realizar aplicações em taxas variáveis ou localizadas somente na área de interesse, consequentemente há uma economia de produto (Luchetti, 2019). Ainda, como vantagem, Assaiante et al. (2020) relatam que além da pulverização, as RPAs podem-se realizar o mapeamento de pontos de irrigação, estimativa de áreas com erosão do solo, focos de incêndio, exploração de áreas de difícil acesso e áreas para abertura de estradas.

Embora haja diversos trabalhos e estudos demonstrando as vantagens da aplicação via RPAs, em outros países, no Brasil observa-se uma carência de estudos em relação ao tema. Entretanto, o número de prestadores de serviço e usuários tem crescido de forma exponencial. Sendo assim, esse trabalho teve a finalidade de desenvolver e avaliar uma RPA para a aplicação de agrotóxicos.

\section{Metodologia}

O trabalho foi desenvolvido no Instituto Federal de Minas Gerais, Campus Bambuí, Bambuí - MG, nas dependências do Laboratório de Mecânica Agrícola. No desenvolvimento da pesquisa, empregou-se a metodologia cientifica estabelecida por Koche (2011).

Para dar início ao desenvolvimento da aeronave remotamente pilotada (RPA), projetou-se um aeromodelo com características de voar a baixas altitudes, baixa velocidade e com boa capacidade para transportar carga. Foi projetado um aeromodelo asa alta, com envergadura de $1.200 \mathrm{~mm}$, comprimento de $900 \mathrm{~mm}$, e a fuselagem com $75 \%$ do tamanho da envergadura. 
A fuselagem da RPA foi construída em uma chapa de poliestireno extrudado com espessura de 5 mm, mais conhecido como depron. Após o projeto da RPA, foi transferido para a chapa e realizado os cortes (Figura 1).

Figura 1. Cortes em poliestireno extrudado para confecção da fuselagem da RPA.

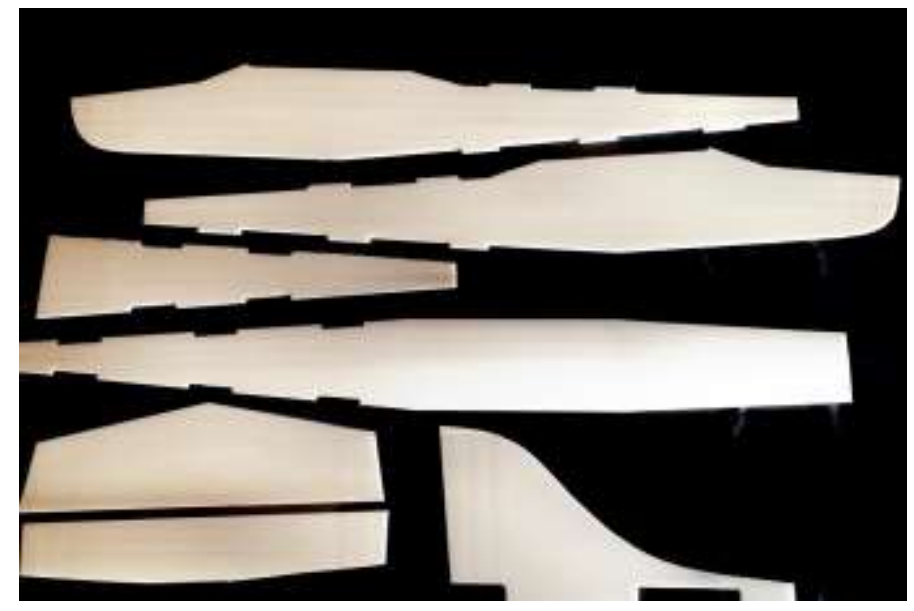

Fonte: Autores.

O estabilizador vertical, e o horizontal juntamente com o leme e o profundor também foram construídos em poliestireno extrudado.

Para montar a fuselagem central do avião, utilizou-se adesivo termoplástico para união das peças. Após coladas, todas as bordas foram lixadas para obter melhor acabamento e também a fim de se evitar arrasto durante os voos. Varetas de fibra de vidro foram colocadas para servirem de apoio para a fixação da asa.

A construção da asa da RPA foi realizada utilizando-se como material principal Isopor T7, um material com alta densidade e baixo peso $\left(\mathrm{D}=32,5 \mathrm{~kg} \mathrm{~m}^{-3}\right)$. Para aumentar a resistência da asa foram instaladas duas varetas de fibra de vidro na parte superior e inferior. Essas varetas foram instaladas paralelas umas às outras, evitando a torção e a flambagem da asa.

Para maior proteção e acabamento estético revestiu-se totalmente a RPA com fita adesiva na cor vermelha, aumentando a visibilidade, facilitando o controle visual durante os voos e também a fim de evitar arrasto. Posteriormente, todas as partes foram unidas e coladas com adesivo termoplástico. Por fim foi feito a instalação do trem de pouso e a fixação da asa na RPA.

Para o controle da RPA, foi utilizado um sistema de rádio controle. Utilizou-se um rádio transmissor (marca Turnigy®, modelo 9x com frequência de $2.4 \mathrm{GHz}$ ). No interior da aeronave foi instalado um receptor compatível com o transmissor, o mesmo recebe o sinal e transmite para as diversas partes eletrônicas da RPA. O sistema de controle remoto instalado possui um alcance de $1.500 \mathrm{~m}$, e além de controlar e operar a RPA, pode-se acionar remotamente todo o sistema de pulverização. Também, foi instalado um GNSS (marca Bryton, modelo 530) para medir a velocidade média de deslocamento.

Para a movimentação da RPA, foi instalado um sistema eletromecânico. Utilizou-se quatro servomotores, sendo que dois deles foram instalados na asa, movimentando-se os ailerons e os outros dois foram instalados nos estabilizadores vertical e horizontal, um servomotor ligado ao profundor e outro ligado ao leme.

O sistema propulsor instalado foi um motor Brushless (marca Turnigy, modelo 3536 de $1.450 \mathrm{kV}$ ). Para variar a aceleração, foi diretamente ligado ao motor um controlador eletrônico de velocidade de 60 A. No motor foi instalado uma hélice com especificação técnica de 10x6, que apresentou 10 polegadas de comprimento e $6 \mathrm{~mm}$ de passo.

Para o sistema de pulverização, foi instalado um tanque com capacidade de 0,350 L e para pressurizar o líquido, utilizou-se uma bomba hidráulica (marca CFACIL, modelo Robótica com vazão de $120 \mathrm{~L} \mathrm{~h}^{-1}, 12 \mathrm{~V}$ ). A barra de pulverização 
utilizada na RPA (marca Jacto®, com 500 mm de comprimento) foi dotada de duas pontas de pulverização hidráulica (marca Jacto®, modelo JD 12P), uma ponta em cada extremidade da barra. O acionamento do sistema de pulverização foi realizado pelo rádio controle.

Após o desenvolvimento da aeronave, prosseguiram-se as avaliações da pulverização. Para avaliar a faixa útil e qualidade da pulverização da RPA, montou-se um experimento, em condições de laboratório, realizando-se aplicações de água em papéis hidrossensíveis. Durante o experimento, isolou e monitorou o tráfego de pessoas e veículos em um raio lateral de no mínimo $50 \mathrm{~m}$ do local. A aeronave operou a altura máxima de $20 \mathrm{~m}$ do solo e sempre visível ao operador.

$\mathrm{Na}$ avaliação da faixa útil de aplicação, montou-se um experimento em delineamento inteiramente casualizado, em esquema fatorial $(3 \times 7)$, três alturas de voo $(1,0 ; 2,0$ e 3,0 m) e 7 etiquetas distribuídas horizontalmente a direção do voo, espaçadas entre si de $0,50 \mathrm{~m}(-1,5 ; 1,0 ;-0,5 ; 0,0 ;+0,5 ;+1,0+1,5 \mathrm{~m})$, totalizando uma faixa de avaliação de $3 \mathrm{~m}$ (Figura 2$)$. Todo o procedimento foi repetido por quatro vezes, totalizando 84 unidades amostrais.

Figura 2. Avaliação da qualidade da aplicação.

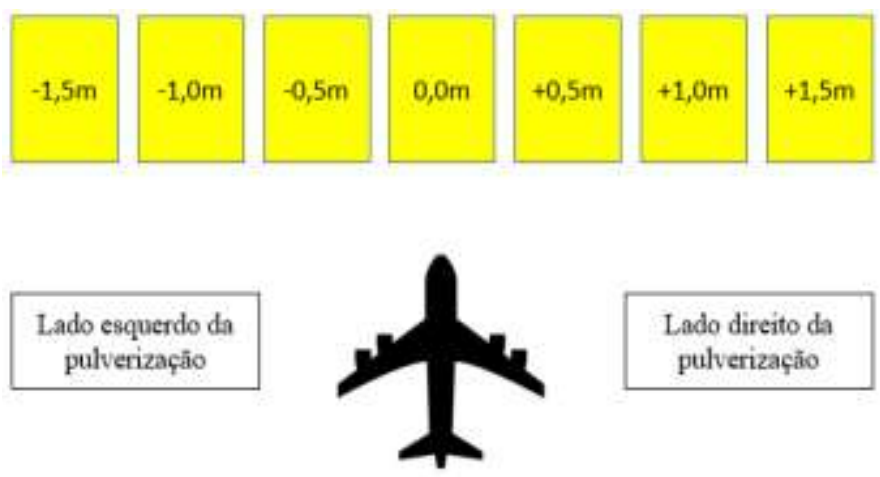

Fonte: Autores.

As pulverizações foram realizadas tomando-se como referência a posição central da faixa de avaliação $(0,0)$. Padronizou-se o sinal negativo e positivo as etiquetas posicionadas ao lado esquerdo e direito, respectivamente, do sentido do voo.

A velocidade média de deslocamento da RPA durante as avaliações foi de $20 \mathrm{~km} \mathrm{~h}^{-1}$. As pontas de pulverização apresentaram vazão média de líquido de $0,160 \mathrm{~L} \mathrm{~min}^{-1}$. A temperatura do ar no momento da pulverização foi de $25{ }^{\circ} \mathrm{C}$, umidade relativa de $45 \%$ e velocidade do vento de $12 \mathrm{~km} \mathrm{~h}^{-1}$. A RPA foi controlada remotamente de forma manual, e, para aplicação na altura correta, foi colocado uma baliza, ao lado das etiquetas (Figura 3A). Sob o solo foi colocado uma barra de alumínio com a posição exata das etiquetas (Figura 3B). Em seguida, realizaram-se as pulverizações (Figuras 3C e 3D). 
Figura 3. Avaliação da deposição de gotas sob o alvo. (A) Baliza para referência da altura de voo da pulverização; (B) Papéis hidrossensíveis; (C) RPA e (D) Papel hidrossensível após a aplicação.

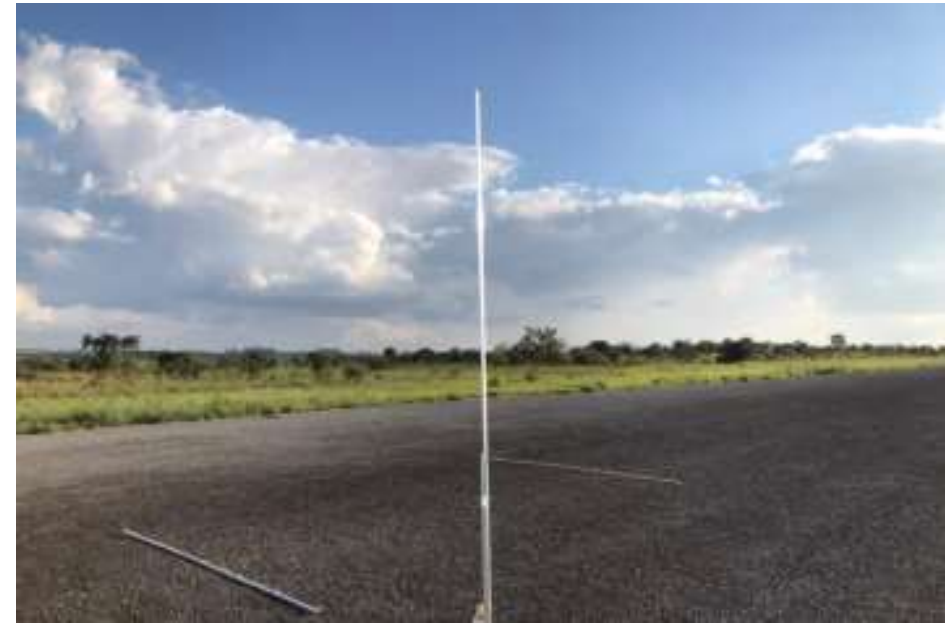

(A)

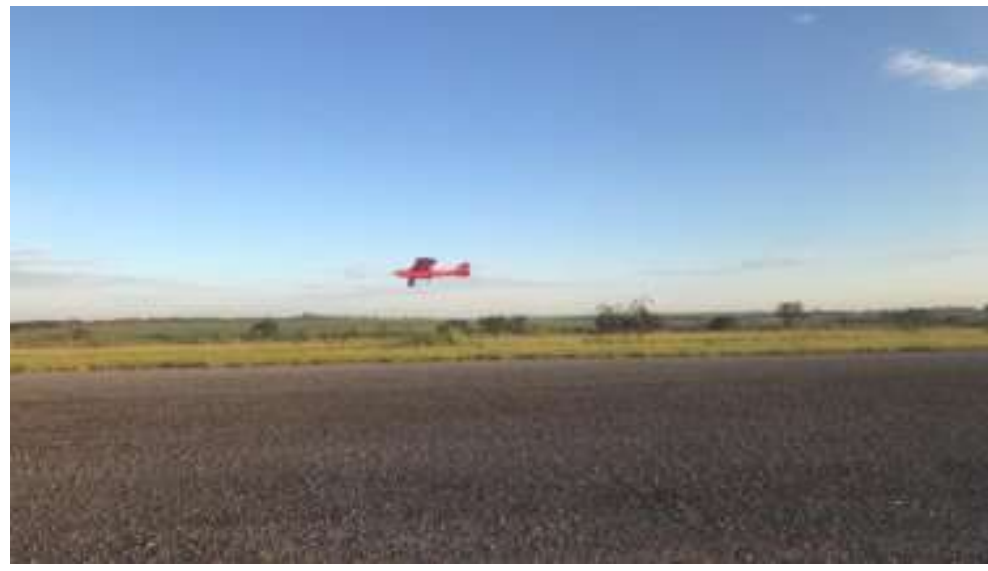

(C)

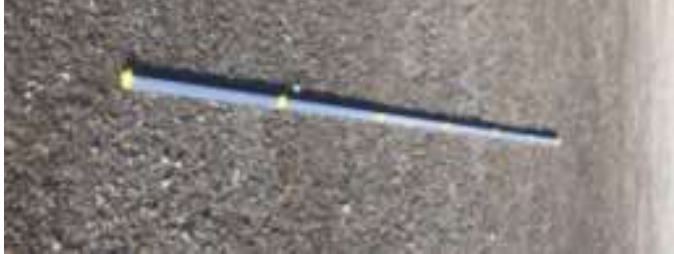

(B)

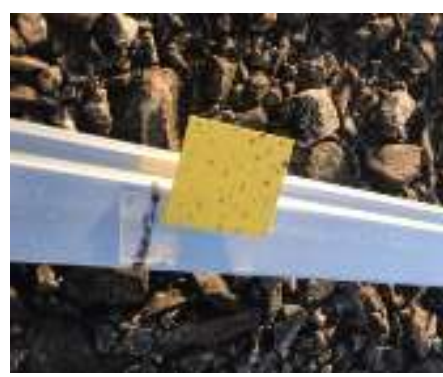

(D)

Fonte: Autores.

Após as pulverizações, as etiquetas foram devidamente identificadas quanto a posição da etiqueta, a altura da pulverização e a repetição da pulverização.

As etiquetas foram fotografadas e analisadas com o auxílio do software para análise de imagens ImageTool 3.0®. Determinaram-se os parâmetros técnicos da pulverização (DMV; densidade de gotas; porcentagem de cobertura do alvo e índice SPAN). Os dados foram submetidos a análise estatística, teste $\mathrm{F}$ da análise de variância (ANOVA), e, quando significativo $(\mathrm{P}<0,05)$ as médias foram comparadas pelo teste de Tukey. As análises estatísticas foram realizadas por meio do software Sisvar® v.5.3.

\section{Resultados e Discussão}

A RPA desenvolvida apresentou estabilidade, baixo custo de fabricação, e possibilidade de realizar as pulverizações no alvo. Na avaliação dos parâmetros técnicos da pulverização, quanto ao parâmetro DMV, constataram-se diâmetros de gotas variando entre 53 e $363 \mu \mathrm{m}$ e houve a tendência de gotas maiores serem depositadas nas etiquetas centrais, reduzindo-se o valor deste parâmetro nas extremidades da faixa avaliada (Tabela 1). 
Tabela 1. Diâmetro da mediana volumétrica (DMV) das gotas de pulverização em diferentes alturas de voo.

\begin{tabular}{cccccccc}
\hline \multirow{2}{*}{ Altura $(\mathrm{m})$} & \multicolumn{5}{c}{ Posição da etiqueta $(\mathrm{m})$} \\
\cline { 2 - 7 } & $-1,50$ & $-1,00$ & $-0,50$ & 0,0 & $+0,50$ & $+1,00$ & $+1,50$ \\
\hline 1 & $77 \mathrm{Aa}$ & $104 \mathrm{Aa}$ & $157 \mathrm{Aab}$ & $328 \mathrm{Ab}$ & $302 \mathrm{Ab}$ & $168 \mathrm{Aab}$ & $57 \mathrm{Aa}$ \\
2 & $227 \mathrm{Bab}$ & $273 \mathrm{Bb}$ & $304 \mathrm{ABb}$ & $231 \mathrm{Aab}$ & $204 \mathrm{ABab}$ & $53 \mathrm{Aa}$ & $57 \mathrm{Aa}$ \\
3 & $252 \mathrm{Bbc}$ & $354 \mathrm{Bc}$ & $363 \mathrm{Bc}$ & $249 \mathrm{Aabc}$ & $64 \mathrm{Bab}$ & $59 \mathrm{Aa}$ & $69 \mathrm{Aab}$
\end{tabular}

Médias seguidas por uma mesma letra, maiúscula na coluna e minúscula na linha, não diferem entre si a $5 \%$ de probabilidade pelo teste de Tukey. Fonte: Autores.

O tamanho de gotas na pulverização de agrotóxicos é um dos parâmetros mais importantes a ser avaliado, uma vez que determina o potencial risco de deriva, potencial risco de perdas por escorrimento, porcentagem de cobertura do alvo e a densidade de gotas. Quanto a variabilidade no diâmetro das gotas ao longo da faixa de pulverização avaliada, podem ter sido ocasionadas pelo vento lateral presente no momento da pulverização, ocasionando o arraste das gotas menores para as extremidades. Ainda, gotas maiores, existe a menor influência meteorológicas no momento da deposição da gota (Sasaki et al., 2016). Costa et al. (2007) relatam que gotas muito finas e finas propiciam maior cobertura do alvo, mas tendem a ser levadas facilmente pelo vento (deriva). Massola et al. (2018) relatam que espectro de gotas e a uniformidade de distribuição volumétrica são parâmetros importantes na seleção da ponta de pulverização.

Com relação à porcentagem de cobertura do alvo, observou-se que a deposição variou entre 0,0 e 3,6\%. Na altura de 1 $\mathrm{m}$, houve maior deposição ao centro da faixa avaliada e na extremidade da faixa $(-1,5$ e $+1,5)$ a porcentagem de cobertura do alvo foi de $0 \%$. Nas alturas de 2 e 3 m, houve maior variabilidade nas deposições das gotas (Tabela 2).

Tabela 2. Porcentagem de cobertura de gotas pulverizadas pela RPA em diversas alturas de voo.

\begin{tabular}{cccccccc}
\hline \multirow{2}{*}{ Altura $(\mathrm{m})$} & \multicolumn{7}{c}{ Posição da etiqueta $(\mathrm{m})$} \\
\cline { 2 - 7 } & $-1,50$ & $-1,00$ & $-0,50$ & 0,0 & $+0,50$ & $+1,00$ & $+1,50$ \\
\hline 1 & $0,0 \mathrm{Aa}$ & $0,2 \mathrm{Aa}$ & $0,8 \mathrm{Aa}$ & $3,6 \mathrm{Ab}$ & $2,7 \mathrm{Ab}$ & $0,1 \mathrm{Aa}$ & $0,0 \mathrm{Aa}$ \\
2 & $0,9 \mathrm{ABab}$ & $1,3 \mathrm{Aab}$ & $1,8 \mathrm{Ab}$ & $0,7 \mathrm{Bab}$ & $0,2 \mathrm{Bab}$ & $0,5 \mathrm{Aab}$ & $0,0 \mathrm{Aa}$ \\
3 & $1,6 \mathrm{Babc}$ & $2,7 \mathrm{Bc}$ & $1,8 \mathrm{Abc}$ & $0,3 \mathrm{Bab}$ & $0,0 \mathrm{Ba}$ & $0,0 \mathrm{Aa}$ & $0,0 \mathrm{Aa}$ \\
\hline
\end{tabular}

Médias seguidas por uma mesma letra, maiúscula na coluna e minúscula na linha, não diferem entre si a 5\% de probabilidade pelo teste de Tukey. Fonte: Autores.

De acordo com os resultados quanto a porcentagem de cobertura do alvo, embora utilizou-se pontas com perfil do tipo cone vazio, na altura de voo de $1 \mathrm{~m}$, observou-se que o perfil de distribuição das gotas foi semelhante ao perfil do tipo leque, conforme descrito por Maciel et al. (2017), o perfil tipo leque ocorre maiores porcentagens do volume no centro do perfil. No presente ensaio, ocorreram maiores deposições ao centro da faixa, e reduzindo a deposição na extremidade. Empregando-se a pulverização por meio da RPA, pode ter ocorrido influência da turbulência do ar, ocasionado pela hélice da RPA, velocidade de deslocamento e altura de voo acarretando em maiores deposições no centro da faixa avaliada. Kullmann et al. (2020) avaliaram a uniformidade de distribuição volumétrica de pontas de pulverização hidráulica com assistência de ar a barra, e constataram que a distribuição é influenciada pelo vento ambiente e vento assistente. Nas alturas de voo de 2 e 3 m, houve maior variabilidade e não foi possível constatar nenhum perfil de deposição.

No presente experimento, a melhor altura de voo foi a $1 \mathrm{~m}$, que proporcionou melhor uniformidade de distribuição de gotas. Para realizar o planejamento da pulverização, recomenda-se realizar simulações de sobreposições entre as passadas, obtendo-se assim a uniformidade de distribuição das gotas. 
A porcentagem de cobertura das gotas pulverizadas é um parâmetro muito importante para saber a deposição das gotas e avaliar a qualidade da aplicação. Ahmad et al. (2020) em um experimento, empregando-se um veículo aéreo não tripulado, relatam porcentagens de cobertura de 36,19\% em seu trabalho, porém empregaram-se um maior volume de calda, o que influenciou diretamente na porcentagem de cobertura. Shan et al. (2021) em aplicações com um veículo aéreo não tripulado, também observaram que a porcentagem de cobertura aumentou com o aumento do volume de calda. Com um volume de calda de 7,5 $\mathrm{L} \mathrm{ha}^{-1} \mathrm{em}$ uma velocidade de $10,8 \mathrm{~km} \mathrm{~h}^{-1}$ apresentaram uma porcentagem de cobertura de 2,7\%, já com uma vazão de $15 \mathrm{~L} \mathrm{ha}^{-1}$ a porcentagem de cobertura chegou a $4,6 \%$.

Quanto a densidade das gotas depositadas no alvo, os resultados obtidos foram semelhantes a porcentagem de cobertura do alvo. Na altura de $1 \mathrm{~m}$ houve uma maior densidade de gotas na etiqueta central $(0,0 \mathrm{~m})$ reduzindo nas extremidades. Nas alturas de voo de 2 e 3 m, ocorreu maior variabilidade na densidade de gotas (Tabela 3 ).

Tabela 3. Densidade de gotas proporcionada pela RPA em diversas alturas de voo.

\begin{tabular}{cccccccc}
\hline \multirow{2}{*}{ Altura (m) } & \multicolumn{7}{c}{ Posição da etiqueta $(\mathrm{m})$} \\
\cline { 2 - 7 } & $-1,50$ & $-1,00$ & $-0,50$ & 0,0 & $+0,50$ & $+1,00$ \\
\hline 1 & $1,9 \mathrm{Aa}$ & $5,5 \mathrm{Aab}$ & $14,1 \mathrm{Aabc}$ & $18,5 \mathrm{Ac}$ & $15,1 \mathrm{Abc}$ & $2,3 \mathrm{Aab}$ & $1,3 \mathrm{Aa}$ \\
2 & $8,5 \mathrm{Aab}$ & $8,5 \mathrm{ABab}$ & $16,7 \mathrm{Ab}$ & $5,7 \mathrm{Bab}$ & $3,2 \mathrm{Ba}$ & $0,8 \mathrm{Aa}$ & $2,1 \mathrm{Aa}$ \\
3 & $20,9 \mathrm{Bb}$ & $18,5 \mathrm{Bb}$ & $8,1 \mathrm{Aab}$ & $2,4 \mathrm{Ba}$ & $0,9 \mathrm{Ba}$ & $1,6 \mathrm{Aa}$ & $2,1 \mathrm{Aa}$ \\
\hline
\end{tabular}

Médias seguidas por uma mesma letra, maiúscula na coluna e minúscula na linha, não diferem entre si a $5 \%$ de probabilidade pelo teste de Tukey. Fonte: Autores.

Na pulverização de agrotóxico, a densidade de gotas a serem depositadas no alvo, depende do produto a ser aplicado e ao alvo a ser atingido. Para alterar a densidade de gotas, deve-se ajustar o espectro de gotas e/ou volume de pulverização. Para um determinado volume de pulverização, Viera et al. (2019) relatam que o aumento do DMV está inversamente relacionado com o aumento da densidade de gotas no alvo. Nas condições avaliadas, observou-se que a densidade de gotas variou entre 0,9 e 20,9 gotas $\mathrm{cm}^{-2}$. Houve variações na densidade de gotas de acordo com a altura de voo. Nas alturas de voo de 2 e $3 \mathrm{~m}$, a variação ocorreu de forma aleatória. Andrade et al. (2018), avaliaram a aplicação de agrotóxicos por meio de RPA e também constataram variações na densidade de gotas de acordo com a altura de voo e tipo de ponta hidráulica. Wen et al. (2018) relatam em seu trabalho variações na densidade de gotas pulverizadas e relatam que pode ser causado pela velocidade do vento natural durante o experimento.

$\mathrm{Na}$ análise da homogeneidade das gotas, embora houve variações quanto aos valores do índice Span, observou-se que não apresentaram diferenças significativas (Tabela 4).

Tabela 4. Índice SPAN.

\begin{tabular}{cccccccc}
\hline \multirow{2}{*}{ Altura $(\mathrm{m})$} & \multicolumn{7}{c}{ Posição da etiqueta $(\mathrm{m})$} \\
\cline { 2 - 7 } & $-1,50$ & $-1,00$ & $-0,50$ & 0,0 & $+0,50$ & $+1,00$ & $+1,50$ \\
\hline 1 & $0,78 \mathrm{Aa}$ & $0,6 \mathrm{Aa}$ & $0,59 \mathrm{Aa}$ & $0,87 \mathrm{Aa}$ & $0,69 \mathrm{Aa}$ & $0,91 \mathrm{Aa}$ & $0,94 \mathrm{Aa}$ \\
2 & $0,56 \mathrm{Aa}$ & $0,42 \mathrm{Aa}$ & $0,66 \mathrm{Aa}$ & $1,71 \mathrm{Aa}$ & $0,83 \mathrm{Aa}$ & $1,62 \mathrm{Aa}$ & $0,80 \mathrm{Aa}$ \\
3 & $0,65 \mathrm{Aa}$ & $0,76 \mathrm{Aa}$ & $0,83 \mathrm{Aa}$ & $2,35 \mathrm{Aa}$ & $0,85 \mathrm{Aa}$ & $1,25 \mathrm{Aa}$ & $0,55 \mathrm{Aa}$
\end{tabular}

Médias seguidas por uma mesma letra, maiúscula na coluna e minúscula na linha, não diferem entre si a 5\% de probabilidade pelo teste de Tukey. Fonte: Autores.

O índice Span, representa a uniformidade no tamanho das gotas. O valor do parâmetro, é ideal quando seu valor é 
zero, porém este valor não é observado nas pontas comerciais devido às mesmas produzirem gotas de tamanhos variados (Sasaki et al., 2016). Valores mais próximos de zero, mais homogêneo é o espectro de gotas. No planejamento e execução da pulverização de agrotóxicos, recomenda-se associar o tamanho de gotas juntamente com o índice Span. Ahmad et al. (2020) obtiveram resultados semelhantes no mesmo parâmetro, comparando as alturas de voo, ambos tiveram pequenas variações. No trabalho de Martin et al. (2019), os dados do índice Span variaram em relação ao modelo de pontas hidráulica utilizada.

Um ajuste aerodinâmico na hélice e fuselagem pode melhorar a distribuição de gotas em ambos os lados e otimizar a qualidade da aplicação. As aplicações com gotas muito finas e finas exigem condições meteorológicas mais amenas para reduzir a deriva. As gotas produzidas podem ser consideradas seguras para uma aplicação aérea. Para a densidade de gotas, cobertura e Span também é possível observar esse efeito.

O equipamento desenvolvido foi utilizado exclusivamente para a aplicação de agrotóxicos. A RPA desenvolvida possui reservatório relativamente pequeno, e recomenda-se a sua utilização principalmente em áreas de pequeno porte, aplicações em áreas localizadas, em locais de difícil acesso ou em plantas de elevado porte. Outras adaptações podem ser realizadas no equipamento, principalmente com relação a capacidade do tanque, que neste caso deve-se observar as características aerodinâmicas da aeronave.

Além do sistema de pulverização, a RPA pode ser adaptada e utilizada na agricultura, como por exemplo, acoplar um sistema de aquisição de imagens para futuras análises e/ou monitoramento de lavouras empregando-se os sistemas remotos. Rokhmana (2015) realizou um estudo prévio e demonstrou o potencial uso de RPA para sensoriamento remoto.

\section{Conclusões}

A RPA, apresentou resultados satisfatórios com grande potencial para utilização para a aplicação de agrotóxicos.

A aerodinâmica do projeto influenciou na qualidade da aplicação entre os lados esquerdo e direito da aeronave.

A RPA possibilita aplicações de agrotóxicos de maneira localizada, em plantas de elevado porte ou local de difícil acesso.

A altura de pulverização que proporcionou melhor qualidade de aplicação foi de 1 metro.

Em trabalhos futuros, sugere-se o estudo da viabilidade de aumentar a capacidade do tanque da aeronave, deriva em condições de campo e validação do sistema proposto em culturas perenes de difícil acesso.

\section{Referências}

Ahmad, F., Qiu, B., Dong, X., Ma, J., Huang, X., Ahmed, S. \& Chandio, F. A. (2020). Effect of operational parameters of UAV sprayer on spray deposition pattern in target and off-target zones during outer field weed control application. Computers and Electronics in Agriculture, 172, 1-10.

Anac (2017). Regulamento Brasileiro da Aviação Civil nº 94. Agência Nacional de Aviação Civil. Requisitos Gerais para Aeronaves Não Tripuladas de Uso Civil. Emenda 00, Brasília. 2017.

Andrade, J. M. A., Pretto, D., Carvalho, E., Bolonhezi, D., Scarpelline, J. R. \& Vieira, B. C. (2018). Avaliação de RPAs para pulverização em diferentes culturas. Revista Ingeniería y Región, 20, 73-78.

Assaiante, B. A. S. \& Cavichioli, F. A. (2020). A utilização de veículos aéreos não tripulados (VANT) na cultura da cana-de-açúcar. Revista Interface Tecnológica, 17(1), $444-455$.

Costa, A. G. F., Veline, E. D., Negrisoli, E., Carbonari, C. A., Rossi, C.V.S. \& Silva, F. M. L. (2007). Efeito da intensidade do vento, da pressão e de pontas de pulverização na deriva de aplicações de herbicidas em pré-emergência. Planta daninha, 25(1), 203-210.

Ferreira, M. C., Leite, G. J. \& Lasmar, O. (2013). Cobertura e depósito de calda fitossanitária em plantas de café pulverizadas com equipamento original e adaptado para plantas altas. Bioscience Journal, 29, 1539-1548.

Gao, J., Liao, W., Nuyttens, D., Lootens, P., Vangeyte, J., Pizurica, A., He, Y. \& Pieters, J. (2018). Fusion of pixel and object-based features for weed mapping using unmanned aerial vehicle imagery. International Journal of Applied Earth Observation and Geoinformation, 67, 43-53. 
Research, Society and Development, v. 10, n. 12, e293101220573, 2021

(CC BY 4.0) | ISSN 2525-3409 | DOI: http://dx.doi.org/10.33448/rsd-v10i12.20573

Kullmann, S. E. \& Dias, V. O. (2020). Uniformidade de distribuição volumétrica de duas pontas de pulverização sob efeito da assistência a ar na barra. Energia na Agricultura, 35 (3), 339-351.

Luchetti, A. (2019). Utilização de drones na agricultura: impactos no setor sucroalcooleiro. Monografia (Bacharel em Ciências Aeronáuticas) - Universidade do Sul de Santa Catarina.

Maciel, C. F. S., Teixeira, M. M., Fernandes, H. C., Vitório, E. L. \& Cecon, P. R. Revista Engenharia na Agricultura, 25(3), 183-199.

Martin, D., Woldt, W. \& Latheef, M. (2019). Effect of Application Height and Ground Speed on Spray Pattern and Droplet Spectra from Remotely Piloted Aerial Application Systems. Drones. 83(4), 1 - 21.

Massola, M. P., Holtz, V., Martins, M. P. O., Umbelino, A. S. \& Reis, E. F. (2018). Spray volume distribution pattern and droplet size spectrum from ceramic nozzles. Agriambi, 22(11), 804-809.

Rokhmana, C. A. (2015). The potential of UAV-based remote sensing for supporting precision agriculture in Indonesia. Procedia Environmental Sciences, 24, $245-253$.

Sasaki, R. S., Teixeira, M. M., Maciel, C. F. S., Alvarenga, C. B. \& Forastieri, P. R. (2016). Espectro das gotas produzidas por pontas de jato plano duplo defasado com indução de ar. Engenharia na Agricultura, 24 (3), 211-218.

Sasaki, R. S., Teixeira, M. M., Fernandes, H. C., Zolnier, S., Maciel, C. F. S. \& Alvarenga, C. B. (2016). Droplets spectrum of air-assisted boom sprayers under different environmental and operational conditions. Agriambi, 20(1), 92-96.

Shan, C., Wang, G., Wang, H., Xie, Y., Wang, H., Wang, S., Chen, S. \& Lan, Y. (2021). Effect of droplet size and spray volume parameters on droplet deposition of wheat herbicide application by using UAV. International Journal of Agricultural and Biological Engeneering. 14(1), 74-81.

Sindag (2017). Relatório de Atividades - Brasil 2016. http://sindag.org.br/wp-content/uploads/2016/12/SINDAG-Relatorio-de-Atividades-Abril2016.pdf

Verger, A., Vigneau, N., Chéron, C., Gilliot, J, Comar, A., Baret, F. (2014). Green area index from an unmanned aerial system over wheat and rapeseed crops. Remote Sensing of Environment, 152, 654-664.

Vieira, L. C., Godinho Junior, J. D., Ruas, R. A. A., Faria, V. R. \& Carvalho Filho, A. (2019). Interações entre adjuvante e pontas hidráulicas no controle da deriva de glifosato. Energia na Agricultura, 34(3), 331 - 340.

Wen, S., Zhang, Q., Deng, J., Lan, Y., Yin, X. \& Shan, J. (2018). Design and Experiment of a Variable Spray System for Unmanned Aerial Vehicles Based on PID and PWM Control. Applied Sciences. 8, 1-22. 